\title{
Ciencia, burocracia y democracia en las políticas públicas: factores actuales para el análisis y evaluación
}

\section{Science, bureaucracy and democracy in public policy: current factors for analysis and evaluation}

Núm. 7 (2016), pp. 64-95

Pinazo Hernandis, Francisco Javier*

JEL Clasif: D7

DOI: $10.5944 /$ reppp.7.2016.16250

Francisco Javier Pinazo Hernandis. Doctor en Derecho por la Universidad de Valencia. Máster en Asesoría Jurídica de Empresas. Abogado especialista en Administración Pública y acreditado para el cuerpo de Profesores Titulares de Universidad en el área de Ciencias Sociales y Jurídicas. Universidad CEUCardenal Herrera. uRL: http://jpinazoh.blogspot.com.es/ . E-mail: jpinazo@uchceu.es 


\title{
Resumen
}

La evaluación de las políticas públicas tiene por objeto investigar si los medios políticoadministrativos aplicados a la resolución de los problemas sociales, permite la consecución de los objetivos asignados. Se trata de analizar en términos de racionalidad instrumental los factores del proceso de políticas, para mejorar la acción en cada uno de sus ciclos o fases nuevas. La evaluación científica en tiempos del cross modern está todavía condicionada por los factores ciencia, burocracia y democracia pero hay que pensar cómo mejorar su instrumentalidad e incluso superarlos. Los tiempos que ya vivimos caracterizados por la complejidad, diversidad/fragmentación y dinamismo, conllevan incertidumbres que exigen nuevas o inconcebibles intelecciones.

Palabras clave: Ciencia; Burocracia; Democracia; Buen Gobierno; Buena Administración; Evaluación científica; Racionalidad instrumental; cross modern

\begin{abstract}
The evaluation of public policies intended to investigate whether the politicaladministrative means applied to solving social problems, allows the achievement of the objectives assigned. This is analyzed in terms of instrumental rationality factors of the policy process to improve action in each of its cycles or new phases. The scientific assessment at the time of Modern Cross is still conditioned by science, bureaucracy and democracy factors but we must think how to improve their instrumentality and even surpass them. The times we live and characterized by complexity, diversity / fragmentation and dynamism, involve uncertainties or inconceivable require new intellections.
\end{abstract}

Key Words: Science; Bureaucracy; Democracy; Good Governance; Good Governance; Scientific Evaluation; Instrumental Rationality; cross modern 


\section{Antecedentes y panorama sobre la evaluación de políticas}

De trazado sinuoso es la historia evaluativa de las políticas asociada a la democracia en el acervo político-administrativo OCDE-UE desde los inicios de la misma en la década de los ' 50 del S. XX hasta el presente. Factores contingentes y culturales, la ideología del gobierno de turno, las creencias religiosas y cosmovisiones axiológicas, las exigencias supranacionales como la incorporación a la UE, la financiación de programas científicos o el mero interés académico han estado muy presentes en esta sinuosidad, que se presenta con trazado poco rectilíneo y claro en su progresión, y a la par, aparece y desaparece en su énfasis.

Posiblemente, dos afirmaciones partisanas nos digan mucho acerca de esta sinuosidad y énfasis, que revela la relación entre la confianza en lo público y la conveniencia, necesidad o exigencia de una acción evaluativa institucionalizada independiente. La primera de ellas se dio en la campaña presidencialista de Robert F. Kennedy en 1968 vs. McCarthy al afirmar el candidato demócrata (...) no vengo a luchar contra otros políticos sino a proponer otra manera de 'hacer políticas' (...). La segunda es la de Ronald Reagan al decir que (...) para qué gastarse recursos en evaluar lo que ya se sabe que se hace mal (...) ${ }^{1}$.

Trabajos previos en esta revista y en otras nos dan cuenta de la historia evaluativa, su institucionalización y su énfasis y a ellos hay que remitirse como antecedentes acerca de cómo el interés político en la evaluación ha pasado ${ }^{2}$ de información a la reasignación desde los '60 a los ' $90^{3}$. En general el panorama internacional es de regresión desde los '80-'90 y no hay motivos de entusiasmo en lo inmediato, aunque en España sí estaríamos ahora ante un panorama mejor por mor de la positivización de la institucionalización evaluativa. Ello aunque solo sea porque la ley 40/2015, de 1 de octubre, de Régimen Jurídico del Sector Público, en su artículo 3 dispone que las Administraciones Públicas deberán respetar en su actuación y relaciones, entre otros, los principios de:

- Responsabilidad por la gestión pública.

- Planificación y dirección por objetivos y control de la gestión y evaluación de los resultados de las políticas públicas.

- Eficacia en el cumplimiento de los objetivos fijados, Economía, suficiencia y adecuación estricta de los medios a los fines institucionales.

- Eficiencia en la asignación y utilización de los recursos públicos.

1 Uno de sus más conocidos eslóganes fue el de que «el mejor Gobierno es el que no existe», al que se suman equivalentes como «El Gobierno es como un bebé: un canal alimenticio con gran apetito en un extremo y ningún sentido de la responsabilidad en el otro»; «El gobierno no soluciona problemas; los subsidia»; «El mostrador de un funcionario es lo más cerca que estaremos de la eternidad en esta vida».

2 Derlien,1998; Peter,1998; Garde, 2004; 2006; Muñoz y otros, 2013; Labeaga,2013.

3 Las funciones propias de la evaluación son: información, reasignación y legitimación.

Revista de Evaluación de Programas y Políticas Públicas | Núm. 7 (2016), pp. 64-95 


\section{2. ¿Evaluación vs. Análisis?}

El análisis o evaluación de la política pública -que por lo común se entienden equivalentes-, tiene por objeto investigar si los medios jurídicos, administrativos y financieros aplicados a dichas políticas permitirían lograr los efectos esperados de dichas políticas y la consecución de los objetivos asignados. En suma supone conocer para mejorar la acción.

La mayoría de las veces se identifica la evaluación con una acción a posteriori, para algún sector doctrinal también puede realizarse tanto en el diagnóstico, como en la fase de programación y se centra en los objetivos de la política o programa y a la par en las necesidades de los destinatarios usuarios o beneficiarios (Gascó, 2002; Pinazo, 2014).

No obstante la equivalencia precitada preferimos acotar la intelección de ambos términos en el sentido de que la evaluación responde mejor a la idea de producto final (output/outcome), mientras que el análisis lo hace con respecto al diseño de ese producto (input), más propio del policy design y del decission making que suelen concretarse en un hacer o no hacer o un hacer de modo diferente.

El análisis ha de consistir en el examen de las consecuencias de las políticas públicas ya existentes o de las posibles innovaciones en su sucesión o transformación, y por ende, serviría a establecer los contenidos y formas de nuevas decisiones públicas, y por lo tanto, en el «qué» y en el «cómo» de ellas. Mientras que la evaluación sería comprobar la consecución de los propósitos. Hay así un nomen para una labor ex ante y ex post. Por simplificar, el análisis es al del diseño de la política lo que la evaluación para su resultado ${ }^{4}$

Pero esta precisión no puede obviar la dificultad del ciclo vital de políticas en el que el proceso implica toda una serie de actividades más o menos relacionadas y secuenciadas. Difícil resulta hallar el origen de una política en una simple decisión o incluso los entresijos e intrahistorias del proceso de decission-making. Esta lectura reduciría el análisis a las intenciones y aciertos de los responsables que elaboran la política hasta su puesta en marcha. La realidad nos demuestra que el resultado final de las políticas está más determinado por las interacciones de los factores y sus variables así como los ajustes continuos que comporta el proceso de políticas, lo que hace que este sea descrito como proceso más que como una acción única (Rose, 1969), decidida en un momento y de manera unilateral ${ }^{5}$.

Muy acertada es la descripción de la política final como resultado de un proceso de aproximaciones sucesivas a un problema, pues como señalara Lindblom (...) La política no se hace de una vez por todas; se hace y se rehace interminablemente. La decisión política es un proceso de aproximación sucesiva a algunos objetivos deseados, en que lo deseado mismo sigue cambiando a cada reconsideración. Hacer política es, en el mejor de los casos, un proceso difícil. Ni los sociólogos ni los políticos ni los administradores públicos saben lo bastante acerca del mundo social para evitar cometer errores repetidos al predecir las consecuencias de las medidas políticas (...) (Lindblom, 1959).

$4 \quad$ No obstante hay que distinguir otra acepción del policy analysis que la distingue del policy sciences como resultante de la inmediata ruptura y distinción entre los sinópticos y antisinópticos de la primigenia Ciencia de Políticas. (Pinazo, 2014)

$5 \quad$ Las políticas públicas determinan la política. Cada tipo de política genera una arena de poder específica con su estructura característica, sus élites, su proceso político y sus relaciones o su forma de mediación de intereses (Lowi,1972)

Revista de Evaluación de Programas y Políticas Públicas | Núm. 7 (2016), pp. 64-95 
Súmese la idea de evaluación como como exigencia democrática (Bañón, 2002) y la posibilidad de deliberación, pluralismo y participación (de la burocracia y de la sociedad) como característica de la perspectiva del welfare state y sobre todo considerado su origen primigenio, lo que no supone que estas no existan en otros contextos no democráticos ${ }^{6}$. Otra cosa es qué nombre ${ }^{7}$ deberían recibir en función de los elementos constitutivos de estas, al menos de este sustancial requisito de la evaluación.

\section{Las políticas del buen Gobierno y la buena Administración}

Para la gestión pública actual el «buen gobierno» requiere que el ejecutivo sea políticamente responsable y capaz de formular e implementar políticas públicas sustantivamente valiosas. Exigencias que solo pueden satisfacerse si el gobierno ejecutivo incluye un cuerpo de funcionarios profesionales separado, pero subordinado al ejecutivo político (Aucoin, 1995).

La «buena administración», sana gestión o buen hacer administrativo es algo más que técnica aplicada. Es un arte, es ética y es filosofía. Es un principio que se comprende como el conjunto de reglas que rigen la gestión de las instituciones públicas y que impone a estas últimas un comportamiento que permita alcanzar un equilibrio entre el respeto de los derechos de los administrados y la preservación de buen funcionamiento del sistema de Administración Pública.

Un aspecto relacionado con esto es que el Gobierno-Administración obtenga además la legitimación institucional por lo que hace, no por su origen. Se considera «buena institución» a aquella que lleva a cabo con eficacia la tarea que le ha sido encomendada, pero manteniendo un gran respeto por y con otras instituciones o sus valores. La institución es buena si es capaz de elaborar reglas que restrinjan la maximización individual cuando es colectivamente destructiva, y si además, es capaz de hacer cumplir estas reglas. La Administración será buena institución si pondera todos los intereses de las redes de políticas, haciendo que prevalezca el interés público, como expresión de la sinergia de todos aquellos intereses colectivos en juego para el desarrollo de la colectividad (Pinazo, 1997).

Como filosofía y praxis en el proceso de políticas conduce a la tendencia hacia la óptima asignación y gestión de recursos para responder a problemas colectivos y liberar recursos para destinarlos a otras necesidades siempre existentes en los presente o en lo mediato. Esto tiene un grave déficit en la asignación de roles directivos a personas no aptas, por aptitud y actitud, para la gestión pública y genera serios o irresolubles problemas por mor de un mal diseño de las políticas o por mor del gap en su implementación.

Las alusiones al buen gobierno y Administración Pública no son nuevas, en la literatura del Espejo de Príncipes del S. XVI - precedente de nuestro gobierno político y económico del reino del S. XVIII (equivalente patrio de la Ciencia de Policía-Cameralismo francés y/o alemán)— se hacía eco de ello ${ }^{8}$ La vieja Ciencia de Policía decía que esta

6 Decisionismo,dirigismo, despotismo,totalitarismo,...

$7 \quad$ Vg. Actuaciones públicas, decisiones gubernamentales, programas,planes,...

8 (...) Pero veamos que sabiduría es la que ha de buscar el Rey en sus ministros... Lo que pregunto es si han de ser Filósofos, Teólogos o Juristas... Lo primero digo, que sin duda seria de grande importancia 
Ciencia, burocracia y democracia en las políticas públicas:

factores actuales para el análisis y evaluación

comprende las leyes y reglamentos que conciernen al interior de un Estado y tienden a afirmar y aumentar su poder, hacer un buen uso de sus fuerzas y procurar la felicidad de los súbditos. O que esta ciencia, tenía por objeto conducir al hombre a la mayor felicidad posible dentro de esta vida (De la Mare, 1713; Von Justi, 1756).

La felicidad eudemónica-aristotélica de ayer que debía procurar el buen gobernanteadministrador, responde hoy al modelo democrático del bienestar ,en el que surgió el análisis de políticas por lo que una buena o aceptable gobernabilidad significa progresar, o tratar de mantener el estatus establecido coyunturalmente, lo que dependerá pues, de un juego de interacciones institucionalizado anclado en el buen gobierno, la buena Administración y una educada sociedad civil, lo que nos lleva a seguir manteniendo que un buen gobierno conseguirá buenas políticas, si se dan estas caraterísticas (Pinazo, 2007):

1. Primacía de la ética de la responsabilidad sobre la de la convicción.

2. Respeto al principio de Buena Administración.

3. Aptitud en el decisor público, en terminos de espíritu y de capacidad.

4. Equilibrio en la conjunción de los principios de la Gestión Pública; equidad, legalidad, eficacia y eficiencia.

5. Síntesis entre la racionalidad ideológica y la técnica.

6. Búsqueda de más valor público por innovación y/o incrementalismo.

En suma,las políticas públicas se presentan como variable dependiente de muchos factores políticos administrativos y sociales, (Méndez, 2000) sobre todo cuando se mantiene un enfoque de sistemas. El outcome que recibe la sociedad -en forma de servicios públicos o actos de implementación concretos resultado de la actividad administrativa-, depende en elevado grado del comportamiento organizativo del subsistema político o del administrativo, o, más aún de una lectura metasistémica de Estado (GobiernoAdministración)-Sociedad. (García Pelayo, 1977)

\section{La racionalidad instrumental como presupuesto científico}

\subsection{Racionalidad y sociología comprensiva weberiana: Los tipos ideales}

El objeto del complejo esquema sociológico weberiano es la acción social, siendo la conducta, un término de referencia. Para Weber, la conducta de un tipo puro (ideal) es un concepto que se distancia de la realidad que supone el tipo promedio (real) cuyo proceder se constata empírica y estadísticamente. Esta idealización responde a la idea

para ser buenos consejeros, aver estudiado y saber estas ciencias. Pero quando esto no tengan, basta que sean sabios en lo que toca al ministerio para que son nombrados... Que tenga muy claro ingenio... Que sea leydo en historias antiguas y modernas... Que haya hecho jornadas y visto tierras diferentes... Que sepa lenguas... (...) (De Santamaría,1615).

(...) No todas las experiencias, como ni todas las virtudes, convienen a los cargos públicos, sino solamente aquellos que miran al govierno político en la parte que toca a cada uno. ... dar las dignidades a un inexperto es donativo, a un experimentado recompensa y justicia (...) (Saavedra,1655). 
de racionalidad instrumental de adecuación de medios a fines, sirviendo para el conocimiento de la realidad. Mediante el grado de aproximación de un fenómeno histórico a estos conceptos típicos, quedan tales fenómenos ordenados conceptualmente9.

Así el político y el funcionario se presentan funcionalmente ideales para el logro eficaz de la política a través de la administración burocrática. Se desarrolla así posibilidad de comprender la acción social a través de la racionalidad de los tipos ideales que se contrastan con las desviaciones empíricas. Es pues un recurso socioanalítico el contraste entre un político diletante y un político que vive apasionadamente para la política, y a su vez, este es contrastado con un funcionario que no se apasiona, sino que sirve objetivamente mediante su teckne. Los roles tipo psicológicos o éticos son meramente metodológicos ${ }^{10}$, una analítica propia de la sociología comprensiva weberiana ${ }^{11}$, en la que lo comprensivo tiene por objeto la política como la dirección o la influencia sobre la dirección de un Estado como el mismo Weber afirma en El Político y el Científico. (Pinazo, 2015). El tipo ideal o construido no se forma como promedio de una totalidad, sino que es el resultado de acentuar unilateralmente un punto de vista «ejemplar» o «axiológico». Refleja el intento de avance en la formación de conceptos sociológicos desde una etapa de descripción y generalización empírica hasta la construcción de sistemas teóricos o modelos. El método del tipo construido es fundamental para la moderna ciencia y tecnología del cambio social en las organizaciones complejas (Campero, 1980).

\subsection{Racionalidad legal burocrática}

Diría Weber en Economía y Sociedad que (...) la consideración no se satisface con el hecho inequívoco (relativamente) y puramente formal de que se proceda y calcule de modo racional con arreglo afines con los medios factibles técnicamente más adecuados, sino que se plantean exigencias éticas, políticas, utilitarias, estamentales, igualitarias o de cualquier otra clase, y que de esta suerte, se miden las consecuencias de la gestión económica - aunque sea plenamente racional desde el punto de vista formal, es decir, calculable-con arreglo a valores o a fines materiales (...) $)^{12}$

9 En la obra El capitalismo y la ética protestante ya se advierte que el tipo ideal es el objeto de investigación y no el tipo corriente dado empíricamente, pues los tipos puros se encuentran muy raramente en la realidad. (Vg. el del empresario capitalista, señalando que nada tiene que ver con el vulgar ricachón, ostentoso, propenso al goce del lujo inútil o consciente del poder. Este empresario presenta rasgos ascéticos, es sinceramente modesto. Nada de su riqueza lo tiene para su persona; solo posee el sentimiento irracional de cumplir buenamente su profesión).

$10 \quad$ Como lo son el homo faber y el homo sapiens.

11 (...) Ya no es posible que esa nación pueda ser gobernada solo por diletantes. ... Ya no es suficiente la administración de diletantes... Necesidades puramente técnicas e ineludibles de la Administración impulsan esta evolución.

...O se vive «para» la política o se vive «de» la política. La oposición no es en absoluto excluyente. Por el contrario, generalmente se hacen las dos cosas, al menos idealmente; y, en la mayoría de los casos, también materialmente... La diferencia entre el vivir para $y$ «el vivir de» se sitúa entonces en un nivel mucho más grosero, en el nivel económico. Vive «de» la política como profesión quien trata de hacer de ella una fuente duradera de ingresos; vive «para» la política quien no se halla en este caso.

... El político profesional que vive de la política puede ser un puro «prebendado» o un «funcionario» a sueldo. $O$ recibir ingresos provenientes de tasas y derechos por servicios determinados (las propinas $y$ cohechos no son más que una variante irregular y formalmente ilegal de este tipo de ingresos), o percibir un emolumento fijo en especie o en dinero, o en ambas cosas a la vez (...) (Weber,1993).

12 Aquí la distinción entre Racional formal y material.

Revista de Evaluación de Programas y Políticas Públicas | Núm. 7 (2016), pp. 64-95 
Ciencia, burocracia y democracia en las políticas públicas:

factores actuales para el análisis y evaluación

Añadiría que la administración burocrática significa dominación gracias al saber. Este representa su carácter racional fundamental y específico. El espíritu normal de la burocracia racional, hablando en términos generales es el siguiente:

1. Formalismo, exigido ante todo para garantizar las oportunidades y probabilidades personales de los interesados, cualquiera que sea su clase, porque de otra suerte las arbitrariedades serían la consecuencia y el formalismo es la línea de menor resistencia.

2. Inclinación de los burócratas a llevar a cabo sus tareas administrativas de acuerdo con criterios utilitario-materiales en servicio de los dominados, hechos felices de esta suerte.

Weber en la obra precitada señala igualmente que (...) Una vez eliminado el capitalismo privado, la burocracia estatal dominaría ella sola; las burocracias pública y privada, que ahora trabajan una al lado de la otra y por lo menos posiblemente una contra la otra, manteniéndose pues hasta cierto punto mutuamente en jaque, se fundirían en una jerarquía única a la manera, por ejemplo, del antiguo Egipto, solo que ahora de una manera incomparablemente más racional y por tanto menos evitable (...)

El progreso industrial y económico que acontece en las postrimerías de la Primera Guerra Mundial exige comprender la realidad político-administrativa de su tiempo como una unidad que exige una racionalidad de medios a fines. Si el Estado quiere modernizarse y ponerse a la altura de su tiempo debe contar con unos medios idóneos en su seno que la dirijan (políticos) y otros que la manejen (funcionarios).

De la misma manera que, el progreso hacia el capitalismo es la modernización de la economía, la racionalidad burocrática constituye el progreso hacia el Estado moderno, el cual funciona como una empresa, con las mismas características que una fábrica, cuyo fundamento económico, reside en la separación del trabajador de los medios materiales de producción. Burocracia y mecanización parecen ir de la mano - sobre todo por los éxitos en aquel entonces industrial del taylorismo y el fordismo-.

El modelo burocrático weberiano constituiría un pilar fundamental de la teoría clásica de la organización moderna (estructuralista) para impulsar los grandes procesos administrativos en los sectores industriales y, a partir de la era del progreso, en los servicios públicos. Científicamente hablando la burocracia moderna o weberiana es un modelo o técnica de organización de medios materiales y de funciones personales que actúa racionalmente bajo los principios funcionales de generalidad, racionalidad, imparcialidad, eficacia e impersonalidad. El énfasis queda fijado en la eficiencia técnica y en la estructura jerárquica de la organización. La propuesta estructuralista desde Weber -tenido como su fundador - considerará como elementos comunes a todas las organizaciones a la autoridad, la comunicación, la estructura de comportamiento y la de formalización.

Tanto Merton, Selznick o Gouldner configuraron teorías críticas de Weber y que desde posiciones distintas sugirieron - con toda razón- que el tipo ideal de estructura y funcionamiento en términos de las relaciones formales entre los agentes, no toma en cuenta que la organización - aún muy estructurada y mecanizada- siempre es condicionada e influida por factores de la conducta humana, que no se pueden ignorarse o soslayarse. 
La posterior escuela neoestructuralista (Etzioni, Blau, Scott, Crozier, Mayntz, Thoenig,...) se presentará como una síntesis de las corrientes de la administración científica y de las relaciones humanas, es decir, supone el intento de conjuntar en un mismo análisis las dimensiones estructural y procedimental con la dimensión personal individual y colectiva. Establecerá así un conjunto de prescripciones en forma de técnicas orientadas a la suavización, la dirección y el control de los conflictos dentro de una organización ante la imposibilidad de resolver todos los problemas y las contradicciones estructurales. (Ramio-Ballart, 1993).

El Estado al igual que las asociaciones políticas precedentes, es una relación de dominio sobre la colectividad basada en el medio de la coacción legítima, que precisa que los hombres dominados se sometan a la autoridad dominante, bien tradicional, carismática o legal. En la modernidad los poderes políticamente dominantes se apoyan en el EstadoAdministración como empresa de dominio que está siempre dispuesta de los elementos necesarios para el empleo físico de la coacción, a saber, el cuerpo administrativo y los medios materiales de administración. Este cuerpo administrativo - de dirección y ejecución-, como representante legítimo ${ }^{13}$ de la empresa política de dominio no solo es garante de la obediencia en virtud del tipo de legitimidad de la autoridad si no debido al interés personal que supone la retribución material y el honor social.

En el capítulo «La empresa estatal de dominio como administración. Dirección política y burocracia» de Economía y sociedad, Weber señalará que en el Estado moderno, el verdadero dominio, reside en el manejo diario de la Administración, por parte de la burocracia, militar y civil. Este Estado funciona como una empresa, con las mismas características que una fábrica, cuyo fundamento económico, descansa internamente ante todo en el cálculo. Esta empresa necesita para su existencia una justicia y una Administración cuyo funcionamiento pueda calcularse racionalmente por normas fijas generales con tanta exactitud como puede calcularse el rendimiento probable de una máquina. La legitimación de la dominación burocrática se encuentra en este principio y en el aseguramiento del funcionamiento impersonal de la Administración. La organización económica capitalista europea, se sustenta desde la racionalidad y el cálculo, aspectos que se extiendes a todos los aspectos de la cultura occidental. La racionalidad consiste en la organización de la vida mediante la división y coordinación de las actividades sobre la base de un estudio preciso de las relaciones entre los hombres con sus instrumentos y su medio ambiente en vista de una mayor eficacia y crecimiento. Se trata, pues, de un puro desarrollo práctico operados sobre sobre el genio técnico del hombre. Unos hombres ideales serán los directores y ejecutores de este proyecto racional de desarrollo social.

«Socialización creciente significa también de manera inexorable, burocratización creciente» diría asimismo Weber y la metáfora de una organización funcionando como una máquina sería una poderosa imagen simbólica del funcionamiento organizativo , empresarial, político-administrativo y social y que, sobre los efectos actuales de socialización parecer haber ido más allá de lo que pudiera concebir el mismo Weber. Se ha afirmado que no caminamos hacia una posburocracia, - como estadio superador y distinto

13 Y democrático coincidente con el momento de Weimar. Los elementos materiales externos, al igual que en la empresa económica, no son de propiedad de quien los utiliza, lo que supone una diferencia con tiempos pretéritos, en los que en ocasiones había confusión -señores y vasallos al servicio del rey con sus propios medios - en cuanto a que en el Estado moderno - como rasgo esencial del mismo- la separación del cuerpo administrativo, o sea de trabajadores administrativos, de los medios materiales, se ha llevado a cabo por completo. 
Ciencia, burocracia y democracia en las políticas públicas:

factores actuales para el análisis y evaluación

sustancialmente- sino hacia una re-racionalización de la tradicional burocracia weberiana, y que por su extensión a la vida del hombre común ha merecido la denominación de «McDonaldización» al ofrecer a productores y consumidores un marco casi universal de habitos, expectativas, eficiencia, calculabilidad, predictibilidad y control tecnológico. El fin de semana después de ir al cine o a los centros comerciales acabamos en un McDonald o similar, comiendo productos hechos en serie, que difícilmente podemos cambiar al gusto. (Ritzer, 1996).

Ahora el ciudadano puede predecir expectativas con la firma digital, el teléfono móvil, el GPS, la cita previa o la autoevaluación para la acreditación de profesores. A veces incluso la burocracia nos da justamente aquello que el hombre nos ha quitado injustamente, o su contrario. Aparece ahora como inexorable un cross modern ultraburocrático en el sentido de que ofrecerá mayores dosis de expectativas, certezas y seguridad jurídica, que aquella que soñara Weber para los principios del siglo XX.

Pero no puede obviarse que esta nos conduce a la misma «jaula de hierro» de las que nos advertía Weber ${ }^{14}$ en la que los individuos pierden toda posibilidad de control sobre sus vidas como sobre el sistema social donde estas se desarrollan, con el consabido déficit democrático. Y esto se repite con la telefónica móvil, televisiones, automóviles, interactuación con la Administración ${ }^{15}$.

\subsection{Racionalidad y decisión publica}

El presupuesto científico de la racionalidad en la acción pública está asimismo en autores de la Ciencia de la Administración norteamericana. En ese sentido se definió la Administración como un tipo de esfuerzo humano cooperativo que pone un alto grado de racionalidad (Waldo,1964). Para sus contemporáneos Dhal y Lindblom una acción es racional en la medida en que esté correctamente diseñada para llevar al máximo el logro del fin, de tal manera la satisfacción de ese fin exceda a su coste. Por ello en el ejercicio de administración están implícitas las funciones de planeación, teleología y coordinación, de tal manera que la prognosis y la cooperación evitan los esfuerzos y costes innecesarios (Dhal-Lindblom, 1937).

Por lo tanto la Ciencia de la Administración pretende el logro de la cientificidad en la decisión pública, es decir obtener la máxima eficacia y eficiencia en un contexto

14 Lo que se conoce como «metáfora de la jaula de hierro» es una imagen retórica utilizada por Weber en una de las últimas páginas de La Ética Protestante y el espíritu del capitalismo para expresar la pérdida del sentido religioso original que inspiró, al primer capitalismo.

Dice Weber: (...) El estuche ha quedado vacío de espíritu, quién sabe si definitivamente. En todo caso el capitalismo victorioso no necesita ya de este apoyo religioso puesto que descansa en fundamentos mecánicos.

... Nadie sabe quién ocupará en el futuro el estuche vacío, si al término de esta extraordinaria evolución surgirán profetas nuevos y se asistirá a un pujante renacimiento de antiguas ideas e ideales, o si, por el contrario, lo envolverá toda una ola de petrificación mecanizada y una convulsa lucha de todos contra todos; en este caso los últimos hombres de esta etapa de la civilización podrán aplicarse la frase 'especialistas sin espíritu, gozadores sin corazón'. Estas nulidades se imaginan haber ascendido a una nueva fase de la humanidad, jamás alcanzada anteriormente (...)

La frase de Weber como tan habitual sucede fue popularizada por Talcott Parsons al traducir como «jaula de hierro» (iron cage), lo que literalmente de definió como «estuche», "envoltura», "dura como el acero», «férrea envoltura», que a la postre o realmente evocan un caparazón duro y opresivo. (Fidanza, 2005).

15 Suponemos que en términos de libertad de elección.

Revista de Evaluación de Programas y Políticas Públicas | Núm. 7 (2016), pp. 64-95 
económico de recursos escasos. La decisión y la implementación deben obedecer a esta racionalidad, pero siendo este el postulado principal del enfoque técnico, no es el único postulado en juego como veremos a continuación.

La Ciencia Política surgió de la «teoría de la decisión» que estuvo referida a la optimización de todos los efectos de las decisiones y al cálculo de los costos y beneficios vinculados a esas decisiones. La Ciencia Política se centró en el comportamiento de un actor (racional) que alcanzaría una decisión en una situación de información y con una jerarquización clara y completa de la preferencia. El modelo del actor racional asume que los procesos de las decisiones públicas suceden en fases (formulación, decisión e implementación) a través de las cuales el decisor primero analiza el problema y las alternativas y luego toma una decisión racional acerca de cuál opción deberá escoger.

Pero la problemática del decisor político excede de la ética y de la técnica, pues el contexto de juego implica una racionalidad limitada debido a la información incompleta y los valores ambiguos, otrosí del comportamiento organizativo u otras variables muy determinantes ${ }^{16}$. El enfoque racional se halla fuertemente contaminado e influenciado especialmente por la concurrencia de algunos de estos factores:

- La Administración Pública tiene funciones y limitaciones políticas y legales, por lo cual concentra su atención en relativamente pocos valores y alternativas en comparación con las que se tendrían que plantear con el modelo de elección racional.

- No es posible la jerarquización de los objetivos, pues normalmente el administrador debe elegir entre políticas que combinan los valores asociados de distinta manera.

- Los intentos de jerarquizar u ordenar los valores en términos generales y abstractos, de manera que permanezcan constantes, termina siempre por ignorar preferencias marginales importantes, condicionadas por cuestiones tales como las instituciones, las emociones, la información, los valores y escasez de alternativas.

- El juego democrático determina muchas veces una falta de consenso sobre la mejor decisión, en virtud de opciones ideológicas o personales en la multiplicidad de actores a lo largo de los procesos de las políticas.

16 Un enfoque de racionalidad absoluta supondría capacidades intelectuales y fuentes de información y de tiempo que los hombres no tienen, por lo que dicho modelo es adecuado para tratar problemas relativamente simples, en pequeña escala, con pocas variables y dimensiones valorativas limitadas 
Ciencia, burocracia y democracia en las políticas públicas:

factores actuales para el análisis y evaluación

- Los decisores públicos no siempre son personas maduras intelectualmente, lo que determina un obrar errático, pues ni tienen conocimiento ni lo consideran necesario ${ }^{17}$.

- Añádase que si bien la política en sí no es irracional, muchas decisiones de contenido político no siempre son acertadas, ni razonables porque están contaminadas emocionalmente. Las causas más frecuentes son las de (Sharkanski, 1999):

- Populismo.

- Partidismo.

- Clientelismo.

- Ideología.

- Predisposiciones profesionales y técnicas.

- Política burocrática.

- Interés propio.

Vemos pues claramente toda una suerte de actitudes que pueden hacer de un gestor un inepto para servir a los intereses generales, por mor de decisiones sicológicamente contaminadas, que afectan a la racionalidad instrumental de una gestión administrativa funcional y teleológica.

La racionalidad de la decisión excede de lo formal y lo supera materialmente al perseguir valores singulares y escogidos, y que en el marco teórico que se expone son los del desarrollo y progreso democrático. Weber que admiraba el parlamentarismo inglés y por lo tanto el pluralismo y el cambio de valores en la decisión, elegidos por el pueblo cada cierto tiempo, advertiría. del peligro del despotismo de la burocracia, para una democracia basada en la decisión racional como acción emprendedora del político ideal, a actuar como empresario político ${ }^{18}$. Esta labor en el marco de la dominación carismática haría de contrapeso al inexorable e imparable ascenso de la lógica burocrática como dominación social.Así una intelección plausible de la teoría burocrática weberiana nos diría que la racionalidad medios a fines, es lo que guía a la burocracia como instrumento o medio

17 La política no es ajena tampoco a la falta de madurez intelectual cuyos síntomas encuentran en los siguientes rasgos (Rojas, 2005): Desfase entre la edad cronológica y la edad mental; desconocimiento de uno mismo; inestabilidad emocional; poca o nula responsabilidad; mala o nula percepción de la realidad; ausencia de un proyecto de vida; falta de madurez afectiva; falta de madurez intelectual; poca educación de la voluntad; o, criterios morales y éticos inestables.

18 (...) Por eso el político tiene que vencer cada día y cada hora a un enemigo muy trivial y demasiado humano, la muy común vanidad, enemiga mortal de toda entrega a una causa y de toda mesura, en este caso de la mesura frente a sí mismo. La vanidad es una cualidad muy extendida y tal vez nadie se vea libre de ella. En los círculos académicos y científicos es una especie de enfermedad profesional. Pero precisamente en el hombre de ciencia, por antipática que sea su manifestación, la vanidad es relativamente inocua en el sentido de que, por lo general, no estorba el trabajo científico. Muy diferentes son sus resultados en el político, quien utiliza inevitablemente como instrumento el ansia de poder El instinto de poder, como suele llamarse, está, de hecho, entre sus cualidades normales. El pecado contra el Espíritu Santo de su profesión comienza en el momento en que esta ansia de poder deja de ser positiva, deja de estar exclusivamente al servicio de la causa, para convertirse en una pura embriaguez personal. En último término, no hay más que dos pecados mortales en el campo de la política: la ausencia de finalidades objetivas y la falta de responsabilidad, que frecuentemente, aunque no siempre, coincide con aquélla. La vanidad, la necesidad de aparecer siempre que sea posible en primer plano, es lo que más lleva al político a cometer uno de estos pecados o los dos a la vez (...) (Weber,1993,1997) 
organizativo al servicio de la democracia siendo pues, a inicios del S. XX, el mejor medio para el buen desarrollo de la misma y su coadyuvante el sistema económico capitalista en aquel momento sin rivales.

Podría decirse en suma que:

a. La racionalidad que ha hecho prosperar económicamente necesita de un sistema político-administrativo racionalmente equivalente.

b. El equivalente del empresario es el político y el del técnico/científico es el funcionario.

c. El binomio poder económico-político como actividad emprendedora e impulsora hacia el progreso requiere de un continuo teckné científico/profesional actualizado como fundamento del buen funcionamiento del sistema, que se representa en los tipos ideales para el político y el funcionario.

\section{Ciencia y Democracia en la argumentación de las políticas}

\subsection{De la Ciencia de la Administración a las Ciencias de Políticas}

Se ha dicho que la teoría de la Administración pública está amenazada de muerte, acechada por la economía y la Ciencia Política, colocando a su alrededor fronteras impenetrables. Desde que en los '50 del S. XX irrumpiese la escuela del Public Choice (teoría de la elección) y las Ciencias de Políticas, la Administración Pública se ha ido convirtiendo en una referencia sin contenidos.

Se dijo profusamente que la Ciencia de la Administración no supo definir claramente su objeto de estudio ni su metodología propia y, en consecuencia, fue incapaz de acumular conocimientos y de establecer paradigmas (Merino, 2000). Pero lo cierto es que por el momento no ha surgido una teoría alternativa capaz de sustituirla, a pesar de que nunca fue capaz de adelantarse a su tiempo - lo que tampoco puede predicarse de otras ciencias sociales- y su desarrollo ha sido como consecuencia de la necesidad de adecuar el Estado, su Gobierno y Administración a los desafíos del entorno contingente. Ha operado más como disciplina de diagnóstico-descripción que de prospectiva-prescripción. Súmese a estas vicisitudes su incapacidad para resolver el dilema en la praxis entre fines y medios, sobre todo en las dicotomías de política y administración o entre fines políticos y medios técnicos racionales.

No obstante las adversidades y malquerencias hacia la Ciencia de la Administración, hay que notar que muchos de los postulados de la Ciencia de la Administración moderna están contemplados en los sistemas jurídicos y muchas de sus propuestas normativas de buena administración son hoy lege data en el Derecho Administrativo, merced al cual, se sirve el Magistrado para corregir la mala administración.

Frente a las intenciones omniabarcantes e inespecíficas de la Ciencia de la Administración, las Ciencias de Políticas surgieron seminalmente ofreciendo un objeto de estudio preciso y concreto que puede ser estudiado o puesto en práctica: el estudio de las políticas y estudio en las políticas como sugeriría Laswell en su Policy Orientation. 
Ciencia, burocracia y democracia en las políticas públicas:

factores actuales para el análisis y evaluación

Así las Ciencias de Políticas no son continuación de la Ciencia de la Administración, ni su evolución sino más bien su alternativa, ya que desde su origen su estudio no se constriñe al Gobierno-Administración, de manera que este deja de ser un conjunto de órganos ligados por un proyecto político único, para comenzar a ser un productor de políticas, toda vez que estas políticas como productos políticos y demandas sociales centran el análisis.

Sin pretenderlo en sí, las Ciencias de Políticas junto a la crisis fiscal y de legitimación del Estado y la ideológica deconstrucción político-administrativa han contribuido a la disolución científica de la Ciencia de la Administración hacia el análisis de políticas y en la Gestión Pública (Pinazo,2013).

Ahora diferente a los inicios de la Ciencia de la Administración ${ }^{19}$, lo importante no es el «quién», (el Estado y su Administración) sino el «qué» y el «cómo» de las políticas, pero desde la perspectiva del entorno social contingente y democrático en un contexto de economía de mercado. La libertad, la racionalidad y la eficacia son los nutrientes ideológicos, necesariamente ligados a una idea democrática liberal, deliberativa y participativa.

\subsection{La influencia de John Dewey}

En el conocido debate con Lippman, Dewey, además de la cuestión concreta de la comunicación, tenía posiciones más propias de la socialdemocracia en torno al rol del Estado (liberalismo social, comunitario,..) por lo que en su obra de los '20 y '30 del S.XX, buscó integrar la filosofía y los asuntos públicos para la reforma política, la democracia, la educación y el bienestar económico y social. Dewey consideró a la democracia «el límite ideal de la asociación humana» y sus instituciones aseguran una suerte de dominación superior a otras formas de organización social. Para él era tanto un sistema de gobierno como una forma de vida. En el marco de la era progresista americana consideró la educación como factor de progreso. La democracia tenía que nacer en cada nueva generación y la educación sería su comadrona. Pero esta democracia, añadiría, no perdura más que cuando hay una democracia social. Por ello, el Estado está obligado a intervenir allí donde las actividades de un grupo ponen en peligro en riesgo el interés colectivo. Frente a posiciones contrarias se opuso a que por ley se limitaran las facultades de intervención estatal, pues ante determinadas situaciones ello impediría actuar en pro del interés público.

\subsection{Merriam y el fracaso del conductismo}

El nutriente científico del movimiento de las Ciencias de Políticas fue una forma de conductismo multidisciplinario, como reacción a los estudios sociales y jurídicos de los años veinte y treinta. Frente al análisis formalista, legalista de aquellos tiempos la respuesta y punto de arranque era la conducta humana, la acción individual, cruzando fronteras entre las disciplinas, ante los diversos determinantes interconectados: políticos, legales, sociales, económicos y psicológicos, llegando incluso a una metodología ecléctica. La

19 En la Ciencia de la Administración americana, en 1926, Leonard White, en Introducción al Estudio de la Administración Pública señalaba (...) los medios sociales y económicos modernos en que opera la administración y la insistente demanda de un grado cada vez mayor de intervención del Estado imponen la cuestión de si un Estado industrial e intervencionista moderno puede actuar sobre la limitada base de un esfuerzo voluntario $y$, sustancialmente, de aficionados que caracteriza nuestra herencia administrativa (...) 
lingüística, la sociología, la antropología, el derecho, la psiquiatría y la geografía, bajo la inspiración del pragmatismo de John Dewey, buscaron integrar la filosofía y los asuntos públicos, interesándose en la reforma política, la democracia, la educación y el bienestar económico y social.

La intervención pragmática sobre estos asuntos requirió de un análisis y coordinación adecuada de la que se ocuparía Merriam $^{20}$, quien en 1945 publicó su obra Políticas Sistemáticas y representaría el símbolo del pragmatismo conductista, compartiendo la visión de la ciencia social como la herramienta que permite la planificación de un gobierno positivo en un sentido liberal y humanista, sin conflicto entre ciencia y democracia. Merriam consideraba necesaria la producción de conocimiento utilizable, es decir, consideraba que la ciencia debía estar al servicio de la humanidad apareciendo el «hombre de conocimiento y de acción», con un propósito de establecer relaciones fuertes entre la Universidad y la Administración Pública ${ }^{21}$. Como otros contemporáneos suyos, Merriam consideró que la aportación desde la ciencia de conocimiento aplicable mejoraría el desempeño administrativo y acción gubernamental del Estado, generando un «buen gobierno» o un «gobierno ilustrado».

Así pues Dewey y Merriam fueron los prolegómenos intelectuales previos a la Segunda Guerra Mundial. Constituyeron la base de una infraestructura ideológica y científica en el campo de las políticas que, al cristalizar en el pragmatismo de los programas del New Deal, aumentó la confianza en la aplicación real de la ciencia social ${ }^{22}$.

El objetivo científico del análisis era crear un catálogo de la dinámica conductual que, sin pretender universalidad, enseñara, tanto como fuera posible, no solo sobre los factores que predisponen las conductas, sino su observación. Ante esta difícil tarea científica de pretender dominar el mundo multidisciplinario de la teoría y de la acción.

Autores posteriores como Lerner, Dror, Kaplan,... respondieron con un conductismo de segunda generación que denominaron «Ciencias de Política», agregando a los fundamentos teóricos del primer conductismo un énfasis mayor sobre las cuestiones de política y sobre el papel del científico de las políticas. El análisis de las políticas sería visto como: un subconjunto del concepto de lo político; como idéntico sin más a lo político; como inclusivo de otras dimensiones desde una óptica interdisciplinaria; o, como medio para abordar de manera integrada los problemas sociales.

Así que la metodología científica se rebajaría a la única función de prevenir y eliminar el error, de tal manera que la pretensión normativo-ideológica se combina con la pretensión, ahora racional de ser válida y eficaz para lo buscado. Al final la posibilidad de describir leyes generales fue desechada y rechazadas las pretensiones neoconductistas, sosteniéndose que analizar y prescribir políticas concretas es más exigente que solo plantear las grandes cuestiones teóricas.

20 El Departamento de Ciencia Política en la Universidad de Chicago, presidido por Charles Merriam estimuló y coordinó la colaboración interdisciplinaria en su universidad y fundó el Consejo de Investigación en Ciencia Social.

21 Llegaría a presentarse a la alcaldía de Chicago en dos ocasiones, o en sus recomendaciones desde la Comisión Brownlow para hacer más competente la gestión de la administración federal norteamericana y su apología a la ciudadanía activa.

22 Muy señalado científicamente ha sido el caso de TVA (Tennessee Valley Authority Act de 1933) que hoy supone la mayor empresa pública de energía de los EEUU. 
Ciencia, burocracia y democracia en las políticas públicas:

factores actuales para el análisis y evaluación

\subsection{Laswell y las Ciencias de Políticas}

Sería Lasswell el dirigente intelectual de la empresa sistemática de integrar el conocimiento y la acción, en contexto de un visión democrática de la política y sus productos, fruto de la ascendencia intelectual Dewey-Merriam² ${ }^{23}$. La labor de integración sistemática del conocimiento y la acción, requería de cinco «tareas intelectuales» clave: clarificación de metas, tendencias, condiciones, proyecciones y alternativas. Así el análisis objetivo podía ayudar a efectuar las elecciones fundadas en valores, sin perder por ello su carácter científico, pues su tarea de clarificación de las metas era un ejercicio intelectual.

Con Lerner, creó las denominadas «Ciencias de Políticas» en 1951 como propuesta concreta de coherencia entre el conocimiento y la acción de tal manera que el ejercicio intelectual a realizar en esta nueva área de conocimiento supusiera un análisis objetivo como ayuda a las elecciones fundadas en valores, sin perder por ello su carácter científico, dotando así de una infraestructura ideológica - filosófica y práctica- al campo de las políticas públicas.

En su trabajo La orientación de las políticas Laswell propuso para esta tarea intelectual el pasar del To knowledge of... a to knowledge in... de tal manera que el conocimiento de cómo y porqué se producen esas y no otras políticas, permitiría mejorar el producto, tanto en su decisión política como en su actividad administrativa implementadora. Para Laswell la tarea del «conocimiento de» sería objeto de la Ciencia Política, de la Sociología o de la Psicología, debido a sus métodos blandos de descripción, catalogación y explicación. El «conocimiento en», debía ser solo actividad de la Economía, la matemática aplicada y la ingeniería, debido a sus métodos analíticos y de modelación para estructurar los problemas y diseñar soluciones (Laswell, 1951) ${ }^{24}$.

La paradoja final fue que los intentos de desarrollar de manera interdisciplinar las Ciencias de Políticas a partir de la premisa de una fortaleza unificadora de un núcleo metodológico común, condujo a las antípodas de lo buscado; su fragmentación en lugar de una integración de una nueva disciplina aplicada con un marco teórico suficiente e idóneo ${ }^{25}$. El mundo académico respondió con dos corrientes cuyas características representaban dos puntos de vista casi antagónicos. Los que adoptaron la expresión Policy Analysis (denominados sinópticos) con orientación empírico-analítica, reemplazaban la política por el conocimiento e identifican el análisis de sistemas como metateoría, el empirismo estadístico como metodología y la optimización de valores como criterio de decisión. Los que adoptaron la expresión «Policy Sciences' (o antisinópticos), se interesaron en el proceso decisorio, reemplazando el conocimiento por la política,

23 Laswell fue discípulo y doctorando de Merriam.

24 El propósito seminal de Lasswell fue dominar las habilidades apropiadas para tomar decisiones ilustradas en el contexto del orden público y cívico (Lasswell,1971).

25 Se ha puesto manifiesto que la ruptura de la unicidad lasweliana estaba ya en los '50-“6o haciendo suya la idea de Lindblom de sinopsis como visión global del todo, reflejada en el análisis de sistemas mientras la visión antisinóptica sostenía la limitación o imposibilidad del conocimiento racional para abarcar sistemas enteros de acción (Garson,1986). 
identificando el pluralismo como metateoría y la racionalidad social como criterio de decisión (Pinazo, 2014). ${ }^{26}$

Para algunos la política era un asunto de valores -ideológico/normativos-, para otros una estrategia, diseño o programa, y para otros abarcaba ambos. De tal manera que dependiendo de la opción, el análisis de políticas más científico en sus formas, que en la sustancia sería.

Esta es la visión genuina del análisis de políticas, con una inexorable unión entre Ciencia y Democracia, como valores del momento político. La Ciencia de la Administración aportaría el conocimiento del enfoque técnico-organizativo y el sociopolítico de la burocracia, de ahí que el análisis de políticas resulte disciplinariamente la conexión de nuevo entre la Ciencia Política y la Ciencia de la Administración, y que en cierta manera es una vuelta a su unión ${ }^{27}$.

\section{La alternativa decisionista (no democrático- parlamentaria)}

Para Karl Schmitt la democracia debe entenderse a partir del concepto de «Estado total», pues este es aquel que ha superado el momento liberal, y se inmiscuye en todas las esferas de la vida en sociedad. Sus críticas al liberalismo, al parlamento como institución y al parlamentarismo como forma de gobierno, resultan incompatibles con su idea de democracia directa, en la que no hay representantes, ni elecciones. Tampoco Schmitt acepta la idea de pluralismo, ya que sostiene que a la democracia le es propia la homogeneidad y la unanimidad y esa unidad política debe hacer desaparecer las diferencias.

La noción de Estado de Schmitt no es la de un Estado neutral y gendarme tal y como fue en el XIX. El nuevo Estado debe recuperar el monopolio de lo político y poner fin a que la economía sea independiente del Estado. El Estado total, debe absorber lo social en el terreno de lo político ${ }^{28}$.

La unidad política es la unidad que en cada momento y de manera determinante representa al «sujeto de la decisión». Nada que sea político es ajeno al Estado y, la decisión de qué es político o qué no lo es, le corresponde únicamente al Estado.

26 El debate teórico mostró el conflicto entre análisis de sistemas y política, métodos cuantitativos y análisis de caso, muy bien reflejado en la dicotomía analistas-bomberos y que institucionalmente, quedó representada en la escuela Harvard de los trituradores de números vs. escuela Berkeley de los politiqueros.

27 A principio del S.XX se afirmaría que la Ciencia de la Administración no es una Ciencia política, sino la Ciencia Política, debiendo estudiar la conveniencia y oportunidad que para la Administración supone organizar y mantener un servicio público y demás circunstancias relacionadas con su funcionamiento. pues para el citado no sería vano que la Ciencia Administrativa se ocupara de la determinación de los fines específicos que el Estado debe proponerse y de la actividad a desarrollar para llevarlo a cabo (Pressutti, 1903). En la historia administrativa también resurgió el movimiento de vuelta a Stein como tratar de unificar de nuevo la Ciencia de la Administración y el Derecho Administrativo, o la vuelta a Colmeiro en versión doméstica.

28 Se ha afirmado al respecto que cuando la palabra «total»o «totalitarismo» aparece en los textos de Schmitt lo hace refiriéndose a una de las siguientes instancias; total en el sentido de una situación que abarca a la «unidad política» completa o bien como el desarrollo histórico de los tipos de Estado, del monárquico, pasando por el Estado de derecho, al Estado total con funciones administrativas en el cual la Sociedad se autorganiza a sí misma. 
Ciencia, burocracia y democracia en las políticas públicas:

factores actuales para el análisis y evaluación

Schmitt introdujo el término «decisionismo» en el prefacio a la edición de 1928 de Die Diktatur, en referencia a los fundamentos legales de la dictadura y la Teoría del Estado de emergencia en el Derecho Constitucional ${ }^{29}$. El decisionismo supone una teoría ética y política según la cual la obligatoriedad de las normas no reside en su fundamentación, sino que está determinada por la decisión de alguien con autoridad. (Schmitt, 1921,1922; Negretto, 1995). La oportunidad del decisionismo propio de un Estado Total estaría en la ausencia o minimización de costes de transacción para la toma de decisiones deliberativas (ponencias, debates, comisiones,...) ya que estas decisiones se toman por un ente más eficiente, sobre todo, sin lugar a rupturas ni desavenencias, oposiciones, ni obstáculos. La decisión es fruto de la racionalidad casi absoluta y por tanto eficacia y eficiencia van a la par. Aquí la decisión ya no es un acuerdo para contentar al pluralismo, a la poliarquía, las élites, a las resistencias frente a los cambios,... y además, la máquina de ejecución administrativa funciona como la línea de producción empresarial, sin fisuras, ni averías, pues todos están unidos en cumplir la decisión adoptada.

La objeción al decisionismo está en que la decisión puede ser errática, incluso perversa o desviada y nadie lo podría reparar. La máquina burocrática de ejecución tampoco podría pararse ante los fines perversos o erráticos. Los modelos totales acaban politizando la ejecución burocrática y esta así, no representa a los técnicamente mejores, sino a los más allegados. El problema es que la historia está llena de razones para obviar este planteamiento habida cuenta de las consecuencias de los totalitarismos del S. XX y los que aún perviven ${ }^{30}$.

El decisionismo puede aportar más eficacia pero sobre todo eficiencia y economía pero su pretendido sentido democrático no es equivalente axiológicamente al triunviro Ciencia, burocracia y democracia que se da en el planteamiento primigenio de las Ciencias de Políticas, si bien hay que reconocer que las dos primeras también estarían en el decisionismo político y en todo caso, términos de historia administrativa no puede obviarse en todo esto que:

- La Ciencia de la Administración se desarrolló eficazmente en momentos absolutistas -Napoleón y el despotismo ilustrado prusiano- y por ello Wilson, ante la necesidad de una Administración Pública moderna y acorde para el fomento del progreso democrático e industrial americano, reconoce las bondades de las administraciones europeas, aunque no le guste su modelo político monocrático ${ }^{31}$.

29 No obstante, ya había utilizado la categoría de decisión para definir su propia concepción de la política frente a la filosofía del romanticismo.

30 Se ha dicho que lo temores de la jaula de hierro de weber se plasmaron en los totalitarismos nazi y estalinista.

31 (...) El objeto del estudio administrativo es descubrir, primero, lo que el gobierno puede hacer legítimamente y bien, y segundo, como puede hacer estas cosas apropiadas con la mayor eficiencia posible y con el menor costo de energía posible, ya sea de dinero o de esfuerzo...

...Por ello, debe haber una Ciencia de la Administración, que tratará de enderezar el camino del gobierno, para que sus empresas tengan más aire empresarial, para fortalecer y purificar su organización, y para coronar sus deberes con obediencia. Esta es una razón por qué hay una ciencia.

Pero, ¿dónde ha crecido esta ciencia? Seguramente no en este lado del mar. No se puede encontrar un método científico en nuestras prácticas administrativas. La atmósfera venenosa del gobierno de la ciudad, los secretos corruptos de la administración estatal...

No, los escritores americanos hasta ahora no han tomado parte en el avance de esta ciencia. Ella ha encontrado sus doctores en Europa. No es obra nuestra, es una ciencia extranjera.

...Talfue el caso de Prusia, por ejemplo, donde la administración va a ser más estudiada y más perfeccionada.

Revista de Evaluación de Programas y Políticas Públicas | Núm. 7 (2016), pp. 64-95 
- La democracia no es el sistema de decisión ni más eficaz ni más eficiente; tiene notables costes políticos y económicos ${ }^{32}$.

\section{Metaanálisis-Metaevaluación de Políticas Públicas}

\subsection{Nula o escasa ciencia en el análisis-evaluación}

Una teoría inductiva desde la observación empírica en la formulación o implementación de las políticas en nuestro contexto nacional o regional diría que el modelo que se sigue es el más opuesto al de maximalismo racional y supone una suerte de «anarquía organizada», equivocidad y ambigüedad. Modelo que se aproxima en mucho al denomina como «cubo de basura/papelera (Garbage Can)» y el cual posee las siguientes caraterísticas (Cohen-March-Olsen, 1972):

- Una decisión es el resultado de la interpretación de muchos flujos relativamente independientes en la organización, en la que predomina buscar un problema para una solución previamente diseñada y/o adoptada.

- Se trata de gestionar un compromiso entre resolver un problema y los apremios de una situación.

- No se busca lo óptimo sino evitar lo peor en función de alternativas privilegiadas por preferidas, predeterminadas o impuestas.

- Los «flujos» se limitan a cuatro: Problemas, Elecciones, Soluciones, Actores.

La dinámica de toma de decisión lógico-racional sería que ante un problema elijamos una solución entre varias posibles y la pongamos en marcha con determinadas personas aptas:

$$
\text { Problema (P) } \rightarrow \text { Elección (O) } \rightarrow \text { Solución }(\mathrm{S}) \rightarrow \text { Actores (A) }
$$

Pero en el modelo papelera se altera esta lógica por cualquiera de estas otras secuencias en la que primero se busca o se impone bien al actor, la solución o la elección ${ }^{33}$. En suma caben tantas combinaciones como se muestran en el cuadro que sigue:

Por consiguiente, la remodelación de la administración francesa por Napoleón es mi segundo ejemplo del perfeccionamiento de la maquinaria civil por la sola voluntad de un gobernante absoluto...

... Por supuesto, toda preferencia razonable se declararía a favor del curso político Inglés y Americano más que por la de cualquier país europeo.

Es más dificil para la democracia organizar la administración, que para la monarquía. ...Se puede pedir prestada la ciencia de la administración con la seguridad y provecho si solo leemos todas las diferencias fundamentales de la condición dentro de sus principios esenciales. Sólo tenemos que filtrarla a través de nuestras constituciones, solo para ponerla a fuego lento de la crítica y destilar de distancia de sus gases de extranjeros (...) (Wilson,1887)

32 (...) los resultados que se obtienen cuando los sistemas democráticos son analizados con las herramientas de la teoría económica, pueden parecer sorprendentes, por lo menos a primera vista. Es posible que la democracia, sin maquillajes ni afeites ofrezca una imagen menos bella y atractiva de la que le atribuyen los románticos (¿̇o los demagogos?). El espejismo puede afectar fácilmente a quienes la conozcan poco y a quienes no hayan vivido de cerca las pesadillas de las dictaduras. El sistema democrático no puede presumir de aquello de lo que carece. Sobre el papel no es el más eficiente ni el más barato, ni tampoco es inmune a las mixtificaciones o a la manipulación. Es, sencillamente, «el peor de los sistemas políticos, si excluimos a todos los demás» (...) (Corona, 1987)

33 De tal manera que lo normal es que la solución o los actores anteceden a todo. Vg. La solución que se adopta está en la contratación del producto «X»(de la red clientelar) o de los actores «Y» (militantes del partido) o en la elección «Z» (hay que privatizar esos servicios, para que los gestionen los tales actores). Jurídicamente un ilícito penal y nulo administrativamente. 


\begin{tabular}{|c|c|c|c|}
\hline $\mathrm{S}$ & $\mathrm{O}$ & $\mathrm{P}$ & $\mathrm{A}$ \\
\hline $\mathrm{O}$ & $\mathrm{A}$ & $\mathrm{S}$ & $\mathrm{P}$ \\
\hline $\mathrm{A}$ & $\mathrm{S}$ & $\mathrm{P}$ & $\mathrm{O}$ \\
\hline
\end{tabular}

Este método describe la ausencia de análisis/evaluación, como también puede explicarlo el ajuste partidario mutuo consecuencia del pluralismo combativo, como enfoque dominante en la Ciencia política. En el abanico de los modelos existentes se encuentran los de máxima racionalidad (sinóptico-comprensivo/normativo óptimo) y los de mínima o nula (cubo basura). Y entre ellos los modelos intermedios (factibilidad, incrementalismos, Allison I, II y III, proceso social...) (Pinazo, 2014).

Lo importante pues es que se haga análisis y no un antidemocrático ejercicio de irresponsabilidad, habiéndose indicado recientemente que la evasión de la culpa configura la vida política y organizativa ${ }^{34}$. Si la dinámica de papelera se hace por motivos perversos se conculca a la par los principios del triunviro. Ni hay ciencia, ni democracia, ni menos aún burocracia $^{35}$. Un examen de la dinámica real nos daría datos si se analizara por ejemplo lo siguiente:

- Si los gabinetes no hacen sino documentar sobre alguna área geográfica o sectorial ante la supina ignorancia o remoto conocimiento de los decisores acerca de los entornos de actuación.

- Si el personal de los gabinetes tiene estudios adecuados o experiencia en la toma de decisiones complejas en estructuras organizativas o incluso nociones básicas de nomotecnia.

- Si en los gabinetes se conocen los modelos teóricos de análisis de políticas, sus problemas o se conocen alternativas analíticas en torno a las propuestas de gobernanza, sistemas comparados, modelos matemáticos, de simulación, de economía aplicada,...

- Cómo se compadecen los ciclos presupuestarios y políticos con el ciclo vital de las políticas y la sistematización de estas (subpolíticas, programas, subprogramas, acciones...)

- Porcentaje de tiempo y de recursos que se dedica al protocolo, actos de marketing, partisanos, atención de la red clientelar y cuanto al análisis de la toma de evaluaciones.

- Si se tiene constancia de los enunciados evaluativos y de su contaminación ad intra o ad extra por mor de propósitos encubiertos.

34 Para él (...) la evasión de la culpa es una forma de vincular tres cosas que normalmente viven en cajones académicos independientes en estos ámbitos de estudio, a saber, la forma en que las organizaciones y los programas públicos se estructuran, la manera en que funciona el mundo de la manipulación de a la opinión pública y la política de los procedimientos rutinarios normalizados que se encuentran en el mundo de los servicios públicos y el gobierno. La evasión de la culpa es una forma de llevar el análisis de todos estos elementos normalmente separados hacia un solo punto, y también de vincular el análisis institucional o de comportamiento sobre el funcionamiento de las organizaciones o el comportamiento de los individuos con ideas acerca de cómo deberían ser las cosas (...). (Hood,2015)

35 Habitualmente el fraude de ley o la desviación de poder se presenta empíricamente más sutil y difícil de mostrar, por el juego de presunciones administrativas. 
- Cuál sería el algoritmo para efectuar evaluaciones con propósitos abiertos -no encubiertos- de conocimiento y mejora.

- Si la dinámica imperante es la del cubo de basura, el ajuste partidario mutuo, o en el mejor de los casos el modelo incrementalista simple o el desarticulado.

- Cuál es el rol o skills distintivos del personal de gabinete, respeto del personal directivo o el de libre designación.

\section{2 ¿Analistas de políticas o meros legitimadores de la decisión?}

El marco teórico normativo sobre políticas, requiere de un tipo ideal de analista desde la racionalidad instrumental para que el mecanismo de apoyo a la toma de decisiones sea espacio para una élite intelectualmente excepcional para la búsqueda de lo óptimo y además factible en la decisión a tomar. El politólogo Y. Dror partió de la hipótesis de que los analistas de sistemas al uso estaban demasiado influenciados por las decisiones de tipo cuantitativo y de obviar la potencialidad de la factibilidad política, mediante el buen uso del poder político. En este planteamiento, son precisamente la creatividad política, la exploración cualitativa y el pensamiento estratégico e imaginativo lo que hace valer el rol del analista. Se apuesta, en contra de la dinámica de la degradación de la decisión pública, por la necesidad de nuevas élites, capaces de invertir el proceso del declive de las capacidades gubernamentales. Dror propone una suerte de superprofesionales de la política, que estén permanentemente entrando y saliendo de las estructuras de Gobierno. Su objeto es estar en el núcleo del desarrollo de las políticas y precisarían de una nueva reforma en la formación tradicional. Se requiere así de una revolución conceptual con dos notas principales; de un lado capacidad de construir puentes entre el conocimiento abstracto, histórico y comparado, con las realidades concretas, que supongan en definitiva, las mejores soluciones a los problemas planteado; y de otra parte, debe combinarse con una nueva capacidad de creatividad política que supere las opciones al uso (Dror, 1995,1999).

En el análisis de políticas hay instrumentos y metodología sobre cómo conducir al político hacia el acierto, siguiendo una serie de pasos en la toma de decisiones; (tiempo suficiente, información cuantitativa y cualitativa razonable, opciones de las alternativas, consecuencias imprevistas, daños colaterales, eficiencias no paretianas...). También hay tendencias (policy constraint) de las que hay que huir: populismo, partidismo, clientelismo,...(Sharkanski, 1999).

El análisis puede aportar contenido, proceso y método, cumpliendo su desiderátum originario de ir orientado ... from to knowledge of..., to Knowledge in... El recurso al análisis no otorga la infabilidad ante el error, pero ayuda para su evitación, aunque sabiendo de que las limitaciones del análisis han sido también descritas por la Ciencia Política (Lindblom,1997) puesto que:

- Ante un problema complejo es imposible encontrar un acuerdo satisfactorio para toda la sociedad.

- Toda política implica beneficios para unos y perjuicios para otros.

- Nadie tiene a su disposición ni la formación, ni los recursos ni el tiempo para realizar un análisis de las alternativas y seleccionar la óptima. 
Ciencia, burocracia y democracia en las políticas públicas:

factores actuales para el análisis y evaluación

- No existe una mejor política definible en ningún campo, tan solo opiniones en desacuerdo, tanto en la política misma como en el análisis de su diseño.

- Lo racional es admitir que nuestras opiniones son juicios de valor sobre lo que debe hacerse, no sobre lo que es mejor. Lo mejor no puede definirse.

- El analista nunca es imparcial, siempre se está más inclinado por unos valores o por un segmento de la población.

- Todos los análisis de políticas son siempre incompletos, y por tanto, inconcluyentes.

- Los gobiernos tiene que decidir, por lo que no se trata de reconciliar posiciones, sino que algunas personas impongan su decisión sobre otras.

Una frase del mismo Lindblom ${ }^{36}$ lo resume claramente al final es la política la que decide, y esto, es más músculo, que cerebro, de ahí que Dror insista en no perder nunca de vista la dimensión política del análisis, que muchas veces era obviada por las posiciones sinópticas.

Pero si el analista se limita a otorgar el visado de la legitimación de lo acordado, fruto bien del consenso, bien de una lectura incrementalista o bien de entender la toma de decisiones como una mera asignación de recursos públicos disponibles, entonces, poca diferencia existe entre este rol y el cometido habitual del personal eventual de confianza travestido de supuesto asesor.

Lejos de un elitismo sesgado o sectario el analista no es un «megahombre», tampoco un mero voluntarista. Lo que se precisa es que sepa buscar el saber necesario y canalizar los aportes necesarios para el problema concreto desde el análisis histórico, comparado, sociológico, jurídico,... y su valor añadido debe centrarse en el logro de la máxima racionalidad en la toma de decisiones o, evitar las máximas restricciones por mor de la falta de tiempo y de información. Ha de aportar la mixtura entre el enfoque científico y el deseo político aplicado al supuestamente racional y legítimo deseo ideológico de innovación o cambio. En este rol el analista debe asesorar al político sobre las posibilidades de éxito o de fracaso en su gestión. Ha de asumir la consciencia de la ambigüedad y de la frustración del mundo de la política, en modo alguno en manos de ingenuos. Tiene en definitiva que ser consciente de que el análisis tiene un límite y muchos de los problemas son insolubles.

Cabe añadir al respecto que en no pocas ocasiones el momento político también busca tanto en sus asesores o funcionarios como en diversos espacios (Universidad, expertos, Think Tanks, evaluaciones encubiertas,...), un supuesto asesoramiento legitimador de su actuación que muchas veces por mor de la falta de ciencia o técnica en la gestión pública genera injusticias, ineficacias, abusos o sobrecostes en los factores administrativos ${ }^{37}$.

\footnotetext{
36 Entiéndase así el sentido de su propuesta normativa en cuanto a que frente a las reglas convencionales que habrán de guiar la investigación profesional al servicio de las políticas públicas serían; búsqueda imparcial del interés público, empeño por el diseño de políticas prácticas, satisfacer las necesidades de los decisores y especialmente ofrecer recomendaciones, habría que optar por: en lugar de búsqueda imparcial del interés público, parcialidad; en lugar de las soluciones posibles, variedad de estudios para liberar el pensamiento de los fallos; en lugar de satisfacer únicamente las necesidades del funcionario, ayudar al ciudadano común; y en lugar de recomendaciones, el diseño de una investigación para cumplir las diversas necesidades urgentes específicas (Lindblom,1994).
}

37 Sobre la dinámica de tomar las decisiones y luego buscar su legitimación formal, puede verse: (...) Hay un inmenso trasiego de informes jurídicos, económicos y técnicos en los expedientes administrativos 
Parece que el tipo ideal de analista según Dror o Lindblom tampoco encajaría con el producto tipo de las escuelas de negocios, los MBAs y demás propuestas propias de una época poco gloriosa para la gestión pública. No es la filosofía gerencialista ni las finanzas las recetas primordiales, pues siendo importante la economía, la clave del éxito organizacional, está por concepto en el valor añadido - valor público- de la política y sus outcomes derivados y externalidades. Se trata de otros valores con los que hay que jugar la partida. Es la equidad, son nuevos escenarios dinámicos, es otro tipo de bienestar el que la política debe procurar.

\subsection{Mejora de los inputs en el proceso de decisión (energía e información)}

De lo anterior se sugiere que un «metaanálisis» o «metaevaluación» debe orientarse en primer lugar hacia el logro de mayor énfasis científico en la decisión, sin obviar lo político, pero que no sea este factor una variable de mucho fuste y que ceda en aquello que es razonablemente de interés público y a la par factible de ejecutar.

El «metaanálisis» debe centrarse también en esos objetivos factibles a cuyo efecto hay que superar los convencionalismos habituales de ayer (incrementalismo, razón de Estado, conservacionismo, rules of thumb, clientelismo, ajuste partidario,...). El hoy está ya anticipado en buena parte por Yezhekel Dror, al proponer la Ciencia de políticas como el estudio de la metapolítica y de que el reto de la política y de su análisis, consiste en ir más allá de la incertidumbre, pensar en lo inconcebible (Dror, 1994, 2001). El cross modern y su incertidumbre al no haber premisas o paradigmas ciertos invita a pensar en lo inconcebible de hoy. Inconcebible puede ser la persona per se como objeto de acción, la lealtad, sinceridad, servicio, crítica, escepticismo, vocación, neutralidad, iconoclastia, ética, imaginación,etc.

Inconcebible puede resultar para el plus de cientificidad deseado una vuelta a los postulados normativos primigenios de la Ciencia de la Administración y la recuperación de algunas prácticas nobles y sanas para que ni el subsistema político ni el administrativo operen como obstáculo funcional

De su parte el modelo teórico de la era de la Administración Pública ortodoxa americana (Wilson, Goodknow, White,...) se basó, entre otros presupuestos en el respeto a la separación dicotomía política-administración como verdad deseable y en que el fin último de la Administración Pública fuese la eficiencia, entendida como el logro de objetivos con el menor gasto de recursos y mano de obra. Sin entrar en la utopía teórica

que de forma silenciosa y discreta contribuyen al acierto y legalidad de la actuación pública

... el encargo de informes jurídicos externos (y aquí pecan todas las Administraciones Públicas) es una práctica reprochable e incongruente con criterios de eficacia, imparcialidad y legalidad.

...Tales informes externos cumplen alguna de las siguientes finalidades (...) Robustecer criterios políticos (...) Sortear informes técnicos poco cómodos (...) Trafico de influencias y prebendalismo para políticos en el banquillo

...el problema supone un coste tremendo para la Administración. Un coste económico por duplicar gastos públicos en dictámenes caros de complacencia. Un coste político porque posibilitan la toma de decisiones que en ocasiones, tras superar la vía administrativa, tropiezan con el severo corrector anulatorio de los Tribunales (...)

Cfr. «Hablando clarísimo de los informes en la Administración» (http://contencioso.es/2015/o6/o5/ hablando-clarisimo-de-los-informes-en-la-administracion/) 
Ciencia, burocracia y democracia en las políticas públicas:

factores actuales para el análisis y evaluación

y otros pormenores de esta etapa veamos experiencias equivalentes y funcionalmente muy positivas para la racionalidad de medios a fines como resulta de los «Axiomas de Whitehall» como teoría y práctica del gobierno parlamentario inglés, anclada en una relación experto/hombre común. Según la misma:

- El funcionario debe presentar a su jefe político todos los argumentos a favor y en contra de un decisión de manera completa e imparcial.

- Una vez se ha tomado la decisión, el funcionario debe llevarla a cabo con total lealtad más allá de sus preferencias.

- El servicio civil es el responsable de la continuidad de la política, es el corrector del gobierno de partido, su única preocupación es el bienestar de la nación y sus propuestas lo son en función del interés general.

- El funcionario guarda absoluta discreción sobre la autoría de la decisión y es el político el que asume la responsabilidad de su éxito o fracaso.

Esta práctica permitió que el transito al laborismo inglés desde 1945 no fue acompañada de purgas entre los directivos ni siquiera en las formas menos drásticas de reajustes generales ${ }^{3}$.

Lo anterior resalta porque hoy nos encontramos con sistemas de función pública, de gobiernos antagonistas de estos axiomas, obsoletos e inadecuados para hoy. Diagnóstico efectuado por Dror al recomendar un esfuerzo urgente en el desarrollo de recursos para la formulación de políticas, necesitadas de un perfeccionamiento moral en los gobiernos y de medidas de salvaguardia ante las decisiones incorrectas, además de modificar los valores fundados en la razón de Estado hacia la razón de humanidad.

Dicho en términos del discurso que seguimos un metaanálisis/metaevaluación significa redirigir la praxis hacia el incremento y mejora de los inputs «energía» e «información», labor que se compadece con esa triple dinámica sincrónica que se propone para la gobernabilidad actual (Dror, 1994, 1996):

- El asesoramiento científico al servicio del Gobierno.

- Fijación e incremento del rol de los analistas de políticas.

- Profesionalización del arte de gobernar.

Si el, proceso industrial propio de la era progresiva americana o del escenario weberiano requería y obtuvo ejemplarmente una administración con fuertes estructuras materiales e institucionalizadas, la Administración Pública del cross modern requiere de un refuerzo en aquellos flujos que permiten un mayor y mejor conocimiento y talento para su gestión

\subsection{Análisis de factibilidad como ejercicio insoslayable de hoy}

El análisis de factibilidad como modelo analítico de políticas se presenta con las siguientes características (Pinazo, 2014):

$38 \quad$ Ante los cambios a implementar se prefirió que junto a los políticos nuevos que no sabían nada, se mantuviesen a los directivos con experiencias tanto en el gobierno con en la nuevas empresas nacionalizadas, a quienes mantuvo niveles retributivos similares a los del ámbito privado. 
- Considera todas las restricciones (policy constraint) relevantes en un contexto de actuación determinado.

- Las restricciones son: sociales, políticas, administrativas, institucionales, técnicas y económicas.

- Las restricciones, limitan durante el proceso decisorio, la gama de elecciones factibles.

- Las restricciones constituyen recursos heurísticos para el aprendizaje, la predicción y la solución de problemas.

Es uno de los modelos analíticos que conjuga una razonable dosis de ciencia y de ajuste partidario entre distintas opciones en un contexto de pluralismo, marcado institucionalismo y política burocrática, lo que le convierte en buen candidato para ir afrontando el incremento pluralista y confrontación entre diversos actores por mor del cross modern.

Se ha señalado la poca o nula importancia que le ha sido conferida a la factibilidad por los analistas de políticas, pues estos se ocupan de las limitaciones que resultan obvias, dejando casi de lado las restricciones políticas e institucionales. En no pocas ocasiones no se ha sabido manejar con determinación e imaginación las restricciones en la implantación de políticas, con el propósito de eliminarlas o en su caso aprovecharlas, para formular nuevos cursos de acción. En el campo de la Administración Pública, el investigador encuentra en el plano teorético o el comparado con soluciones satisfactorias a ciertos problemas, pero que no se pueden aplicar por falta de conocimientos de aptitud, actitud o flexibilidad institucional.

Para Majone los problemas no son posibles o imposibles de resolver en forma general, sino que esto depende de ciertas restricciones o condiciones del mundo real. O sea, que un problema bajo ciertas circunstancias tiene solución y bajo otras carece de ella. Sostiene también que la vida diaria está llena de restricciones, y que debido a la familiaridad con que se abordan no se reconoce su presencia. En el sector público es difícil encontrar soluciones óptimas y hay que adoptar otras que no satisfacen los intereses de toda la sociedad. La factibilidad política no es un tema indiscutible, pues para comprenderla resulta indispensable entender los factores que influyen en las acciones gubernamentales dentro de un marco democrático. Por lo que una política, es o no factible, solo respecto de ciertas restricciones específicas que limitan la acción del gobierno en situaciones particulares.

Por ello es de mucha utilidad que los analistas ayuden en la deliberación pública a evitar que se exageren o subestimen esos límites. Un análisis comprensivo de la factibilidad trata de identificar todas las restricciones reales o potenciales, separarlas de los obstáculos ficticios, evaluar su importancia para diferentes estrategias de ejecución y estimar los costes y beneficios. La praxis desvela que los analistas de políticas se ocupan de manera explícita de unas cuantas limitaciones que se pueden medir con facilidad, como las restricciones técnicas o presupuestarias, pero tienden a tratar las restricciones políticas e institucionales. Pero en realidad no hay diferencia esencial entre las restricciones técnicas, económicas, políticas, institucionales o de cualquier otra clase, ya que todas restringen la libertad del decisor público (Majone, 1975; Meltsner, 1972). 
Ciencia, burocracia y democracia en las políticas públicas:

factores actuales para el análisis y evaluación

Un elemento para superar el reto está en hacer análisis más argumentados y más estratégicos y consecuentemente, más convincentes, tendentes a evaluar la factibilidad política de cada alternativa, lo que dependerá de su diseño inteligente, de la estrategia política y de la habilidad en la implementación factible en términos en función de los contextos situacionales-contingentes (Behn, 1986).

Hic et nunc el subsistema político se presenta como una notable restricción, como demuestra un estudio reciente sobre la Gestión Pública, en la UE - en el que no está España contemplada- es patente la ineptitud de la clase política como dirigente estratégico actual, (Pollitt-Bouckaert, 2010), al advertirse que:

- No hay evidencias convincentes sobre la disposición o capacidad de los responsables políticos para convertirse en gestores estratégicos.

- Lo mejor que puede decirse sobre los modelos de reforma a los que se acogen los políticos es que su validez no está demostrada.

- Los modelos tradicionales no es que sean tanto incorrectos como inadecuados para los tiempos actuales.

- La preparación de los políticos para el desempeño del cargo público ha sido en muchos países un área abandonada por las reformas.

- La desconfianza hacia ellos puede sustentar razones democráticas sólidas para hacer de su preparación un punto fundamental del debate público

Pero aquí nos encontramos no ya con un problema de teoría administrativa de la Ciencia política , sino sobre todo con un problema de teoría política de la Ciencia de la Administración, o por ser más preciso con un problema de teoría democrática; es decir en la legitimación por aptitud y por resultados del responsable político. El metanálisis/ metaevaluación nos dice que es imposible cambiar los inputs de manera inmediata, esto supone una restricción muy alta para la factibilidad e cambios muy innovadores en los términos en que se plantean. La restricción no es culpa del político común, es más una cuestión institucional o ambiental, que hace a la variable contingente muy determinante en nuestro país, e incluso más todavía en zonas diversas, y más allá de la convivencia, a la par, del villano con el héroe, no es factible una universalidad de las propuestas por más que lo normativo así lo exija. Hoy no parecen posibles cambios sustanciales en la aptitud y en la actitud del gestor público, aunque solo sea porque la política determina a las políticas, y más todavía, hoy como nunca, la economía y la incertidumbre a esta, y a la sociedad en su conjunto.

\section{Conclusiones: una trilogía aún válida para la mejora en la capacidad de gobernar}

Vamos a experimentar socialmente cambios inmediatos que exigen modificaciones en el tipo de gestión pública que hoy aún son inconcebibles. Normativamente se precisa no solo una manera distinta de hacer algunas cosas, sino sobre todo, un cambio de la manera de pensar en casi todas las demás.

Se ha descrito por la sociología un «estado de crisis» debido al fantasma de la indignación que ha causado la anti política (corrupción, malversación, dilapidación, descontrol, 
desregulación, ...) que como desgobierno ha generado un sentimiento de ultraje y sensación de nausea e inutilidad. Una crisis que ya no es transitoria acerca de la legitimidad y la representatividad política (Bauman-Bordoni, 2016). Situación que se compadece también con lo que se describe como «adiáfora», referida a la actuación social de situar ciertos actos o categorías de los seres humanos fuera del universo de evaluaciones y obligaciones morales, por mor de la banalización de la cultura y del consumismo. A ello añádase una cultura del temor progresivamente más poderosa y global (Bauman-Donskis, 2015) que se combina con una sensación generalizada de desilusión.

Asimismo la paulatina desaparición del modelo de Estado postwestfaliano apunta hacia otros modos de evitar el divorcio entre poder y política, para lo que se necesita un buen gobierno/administración ya que en modo alguno la experiencia reciente ha demostrado sobradamente que no hemos llegado al fin de la historia político-administrativa, y sobre todo, que en el análisis de las decisiones gubernamentales o en la evaluación de sus productos, queda mucho por hacer.

Sin duda la búsqueda científica de una Teoría de la Administración acorde a los nuevos tiempos debe acompañarse de una metateoría previa de la lógica de la acción del gobierno que supere, en lo factible, las limitaciones racionales y sobre todo la dinámica cainita y entrópica del ejercicio conservacionista del poder, principal artífice del mal gobierno. El buen gobierno debe conducir a la confianza en él por una sociedad concientizada de las limitaciones económicas y humanas, toda vez que el progreso o riqueza de las naciones viene determinado por la calidad de sus instituciones y no por sus recursos naturales, posición geográfica o rasgos culturales (Acemoglu-Robinson,2012).

Ciencia, Burocracia y Democracia siguen siendo los discursos componentes de una trilogía sobre una mejor capacidad de gobernar distinta a la imperante. Siguen validos los tres fustes del pensamiento pionero de las ciencias de políticas que deben estar hoy presentes si se quiere mantener lo sustancial de la legitimación del gobierno democrático. No es preciso un discurso que contraponga estos tres elementos, si se les da el valor y funcionalidad que merecen. Ni el decisionismo es alternativa hoy, ni lo es la tecnocracia, como tampoco la idea de burocracia es contraria a la decisión democrática.

Esto es así si se mantiene la racionalidad instrumental de cada uno de estos discursos, racionalidad de medios a fines, por separado y más aún en su conjunto armónico, pues no deben pretender más que el progreso o el mantenimiento del bienestar colectivo. Las luchas entre estos elementos son disfuncionales y propias de tipologías weberianas no ideales -individuales o socioorganizativas- . El discurso holístico de la trilogía descansa en un sano equilibrio en el triunviro ciencia-burocracia-democracia. Ciencia como pretensión de conseguir la eficacia, eficiencia y economía en los objetivos; democracia como marco axiológico y cultural en la búsqueda de dichos objetivos; y burocracia como técnica organizativa y lógica socialización. De su intelección conjunta y sinérgica, las políticas públicas serán variables dependientes. Hay que encontrar una síntesis dialógica entre la racionalidad ideológica del «qué» político con la racionalidad técnico/científica del «cómo». Esta labor se mejora concibiendo unos políticos ideales, -por emprendedores, apasionados y coherentes con su ideología y forma de vida democrática- y que son apoyados por unos ideales gestores - preparados y eficaces, por disponer de herramientas metodológicas adecuadas y técnica apropiada-. 
Pero para armonizar esta trilogía, no solo en su argumento existencial y funcional, sino para hacerlo con sus propias disfuncionalidades, precisamos de otra manera de hacer las cosas que se muestra hoy como inconcebible y reto a la vez. Este reto es tarea y lugar común para la Ciencia administrativa y para su aplicación la arena concreta de las políticas. Debe concebirse otra manera de pensar y vivir los valores democráticos y la infraestructura del comportamiento político-administrativo. Hemos de mutar los tipos ideales y los tipos reales de las personas y sobre todo de las instituciones.

Pero no podemos ya dejar de contemplar que la obsolescencia llega cada día antes, y hay que pensar en incluso superar lo que hoy sería concebible como lo óptimo, supuesto que esto fuera aún la orientación de las políticas de Laswell, como ejercicio científico en la política. En ello hay que afirmar que las propuestas sobre la capacidad de gobernaradministrar más científicamente siguen siendo válidas para la cara y cruz de una nueva, distinta o incluso, inconcebible gestión de las políticas.

\section{Referencias bibliográficas}

Acemoglu, D. \& Robinson, J. A. (2012). Por qué fracasan los países: los orígenes del poder, la prosperidad y la pobreza. Bilbao: Deusto.

Aucoin, (1995). The new public management: Canada in comparative perspective. Montreal: Institute for Research on Public Policy, 81.

Bañón i Martínez, R. (2002). La evaluación de la acción pública como responsabilidad democrática. En R. Bañón (comp.), La evaluación de la acción y de las políticas públicas (pp. XV y ss.). Madrid: Edic. Diaz de Santos.

Bauman, Z. \& Donskis, L. (2015). La pérdida de sensibilidad en la modernidad líquida. Barcelona: Paidós.

Bauman, Z. \& Bordoni. C. (2016). Estado de crisis. Barcelona: Paidós 2016.

Behn, R. D. (1986). Policy Analysis and Policy Politics. Policy Sciences, 19, 33.

Castillo de Bobadilla, J. (1597). La política para corregidores y señores de vasallos, en tiempo de paz, y de guerra.

Campero, G. (1980). El concepto de tipo ideal y la construcción de modelos para el campo organizacional. Revista de Administración Pública (México), 40.

Cohen, M. \& March, J. \& Olsen, J. (1972). A Garbage Can model of organizational choice. Journal of Administrative Science Quarterly, 1, 1-25.

Corona Ramón, J. F.(1987). Una introducción a la teoría de la decisión política (Public Choice). Madrid: INAP, 8.

Crozier, M. (1995). La posición del Estado frente a otros actores. Gestión y Análisis de Políticas Públicas, 2, 93-99.

Dhal, R. \& Lindblom, C. (1937). Política economía y bienestar. The Study of Public Administration. American Political Science Review, 31, 65. 
Dahl, R. (1947). Ciencia de la Administración Pública: Tres problemas. Public Administration Review, 7 (1), 1-11.

Derlien H. U. (1998). Una comparación internacional en la evaluación de políticas públicas. Gestión y Análisis de Políticas Públicas, 11-12, 13-22.

De la Mare, N. (1713). Tratado de la Policía.

De Santamaría, J. (1615). República y Policía Cristiana para Reyes y Príncipes y para los que en el Gobierno tienen sus veces.

Dror, Y. (1993). Una élite de alto funcionariado profesional para el siglo XXI. La nueva gestión pública: factor de competitividad. Ekonomiaz, 26, 104-119

Dror, Y. (1994). La capacidad de gobernar. Informe al club de Roma. Madrid: Galaxia Gutemberg-Círculo de Lectores, 13 y 24-30.

Dror, Y. (1995). Asesores políticos para los Gobiernos. Documentación Administrativa $n^{o}$ 241-242, 515-531.

Dror, Y. (1997). El administrador público tipo Delta para el Siglo XXI. Revista do Serviço Público, 48 (2), 5-26

Dror, Y. (1996). Fortalecimiento de la capacidad de los Gobiernos en materia de formulación de Políticas. Gestión y Análisis de Políticas Públicas, 7-8, 189-202.

Dror, Y. (1996). Documento presentado a la $12^{a}$ reunión de expertos del programa de Naciones Unidas en materia de Administración y Finanzas Públicas (UNPAN) en Nueva York del 31 de julio al 11 de agosto de 1995.

Dror, Y. (1999). Los analistas de políticas: un nuevo papel profesional servicio del gobierno. J.M. Shafritz y A.C. Hyde (comps.). Clásicos de la Administración Pública (pp. 508-520). México: FCE.

Dror, Y. (2001). Más allá de la incertidumbre: Lo inconcebible. Polis, Revista Latinoamericana, 2, 2-5.

Felippe, B. (1584). Tratado del Consejo y Consejeros del príncipe.

Fidanza, E. (2005). La jaula de hierro cien años después: consideración acerca de una metáfora perdurable. Estudios Sociológicos, vol. XXIII, 69, 845-855.

García Pelayo, M. (1977). Las transformación del Estado contemporáneo ( $1^{\mathrm{a}}$ ed.). Madrid: Alianza Editorial, 25 y 35.

Gascó Hernández, M. (2002). Hacia una sistematización de la evaluación de programas y Políticas Públicas. Gestión de Análisis y Políticas Públicas, 23, 55-65.

Garde Roca, J. A. (2004). La evaluación de políticas y su institucionalización en España. Gestión y Análisis de Políticas Públicas, 30-31, 21-27.

Garde Roca, J. A. (2006). La institucionalización de la evaluación de las políticas públicas en España. Auditoria Pública, 39, 17. 
Ciencia, burocracia y democracia en las políticas públicas:

factores actuales para el análisis y evaluación

Garson D. (1986). De la ciencia de políticas al análisis de políticas: Veinticinco años de progreso. En Análisis de políticas: Perspectivas, Conceptos y Métodos (pp. 149 y ss.). Grenwich: Jai Press.

Hood, C. (2015). El juego de la culpa. Manipulación, burocracia y auto conservación. Madrid: INAP, 13 y ss.

Labeaga, J. M. et al. (2013). La evaluación de políticas públicas en España: Aprendizaje y práctica institucional. Revista de Evaluación de Programas y Políticas Públicas, $1,31-53$.

Lasswell, H. D. (1951). The policy orientation. En D. Lerner \& H. Lasswell (eds.), The Policy Sciences (pp. 3-15). Stanford: University Press.

Laswell, H. (1971). The Emerging Conception of the Policy Science. Policy Sciences, 1, $3-14$.

Lindblom, C. E. (1959). The Science of Muddling Trough. Public Administration Review, $34,78-88$.

Lindblom, C. E. (1994). La investigación social para la elaboración de políticas: quién la necesita y para qué. Gestión y Política Pública, 3 (2), 257 y 284.

Lindblom, C. E. (1997). ¿Cómo adecuar la política en el análisis de políticas? Gestión y Política Pública, 6 (2), 240 y 245.

Lowi, T. (1972). Four Systems of Policy, Politics and Choice, Public Administration Review, 32.

Majone, G. (1975). La Factibilidad de las políticas sociales. Policy Sciences no 6, 49-69.

Meltsner, J. (1972). Political Feasibility and Policy Analysis. Public Administration Review, 23, 859-867.

Méndez Martínez, J. L. (2000). La política pública como variable dependiente: hacia un análisis más integral de las políticas públicas. En J.L. Méndez (comp.), Lecturas básicas de Administración y Políticas Públicas (pp. 75 y ss.). Mexico: El Colegio de México, Centro de Estudios Internacionales.

Merino, M. (2000). De una disciplina sin objeto de estudio, a un objeto de estudio sin disciplina. Administración y políticas públicas desde una perspectiva nacional. En J.L. Méndez (comp.), Lecturas básicas de Administración y Políticas Públicas (pp. 111 y ss.). México: El Colegio de México, Centro de Estudios Internacionales.

Muñoz, A. \& Muñoz, C. (2013). La evaluación de políticas públicas: una creciente necesidad en la Unión Europea. Revista de Evaluación de Programas y Políticas Públicas, 1, 1-30.

Negretto, G. L. (1995). ¿Qué es el decisionismo?. Reflexiones en torno a la doctrina política de Carl Schmitt. Revista Mexicana de Ciencias Políticas y Sociales, 4O, 49-74. 
Peters, G. (1998). El surgimiento, declive y resurgimiento de la evaluación de políticas públicas en el gobierno americano. Gestión y Análisis de Políticas Públicas, 11-12, 23-28.

Pinazo Hernandis, J. (2007). Neoinstitucionalismo y Gobernabilidad. Un enfoque sistémico y prospectivo para políticas de gestión pública en América Latina. Alicante: Universidad de Alicante, 62-63.

Pinazo Hernandis, J. (2013). Administración Pública y Gobernabilidad. De los orígenes a los nuevos paradigmas. Valencia: LowcostBooks, 54 y ss.

Pinazo Hernandis, J. (2014). Evolución de modelos y enfoques para el análisis de la acción pública: del discurso a una nueva dinámica normativa. Gestión y Análisis de Políticas Públicas, 12.

Pinazo Hernandis, J. (2015). ¿̇Ineptitud subespecie de la corrupción? Enfoque sistémico y funcional desde la Ciencia de la Administración. En J. Marco y B. Nicasio (coords.), La regeneración del sistema: reflexiones en torno a la calidad democrática, el buen gobierno y la lucha contra la corrupción (pp.453-468). Universidad CEUUCH-AVAPOL.

Pollitt, C. \& Bouckaert, G. (2010). La reforma de la Gestión Pública. Un análisis comparado. Madrid: INAP, 214-216.

Presutti, E. (1903). Principios fundamentales de la Ciencia de la Administración. Milán: Societá Editrice.

Ramio, C. \& Ballart, X. (1993). Lecturas de teoría de la Organización. Madrid: MAP, vol I, 31 y ss.

Ritzer. G. (1996). The McDonaldization of Society. Thousand Oaks, CA; Pine Forge Press, revised edition.

Rojas, E. (2005) ¿Cómo es una personalidad inmadura?. ABC, 19. 02. 2005.

Saavedra Fajardo, D. (1655). Idea de un príncipe político cristiano.

Sharkanski, I. (1999), Lo que un politólogo puede decir a un político acerca de la probabilidad de éxito o fracaso. En J. M. Shafritz \& A.C. Hyde (comps), Clásicos de la Administración Pública (pp. 990-1007). México: FCE.

Schmitt, C. (1921). La dictadura. Desde los inicios de la idea moderna de la soberanía a la lucha de clases proletaria. Berlín.

Schmitt, C. (1922). La teología política. Cuatro capítulos a la doctrina de la soberanía. Berlín.

Von Justi, J. (1756). Elementos Generales de Policía. Gottingen.

Waldo, D. (1964). Estudio de la Administración Pública, Madrid: Aguilar, 14.

Weber, M. (1997). El Político y el Científico. Madrid: Alianza editorial, 154. 
Ciencia, burocracia y democracia en las políticas públicas:

factores actuales para el análisis y evaluación

Weber, M. (1993). Economía y Sociedad. México: FCE, 64-65 y 173 y ss.

Wilson, W. (1887). El estudio de la Administración. Political Sciences Quaterly, 2 , 197222. 